Molecules 2002, 7, 858-860

molecules

ISSN 1420-3049

http://www.mdpi.org/

\title{
Editorial
}

\section{New Development: A Printed Edition}

Francis F. Muguet ${ }^{1}$, Shu-Kun Lin ${ }^{2,3}$ and Derek J. McPhee ${ }^{4}$

${ }^{1}$ Laboratoire de Mathématiques Appliquées, ENSTA (Ecole Nationale Superieure de Techniques Avancees), 32 Boulevard Victor, F-75739 Paris Cedex, France. Tel. (+33) 1.45.52.60.19; Fax : (+33)

1.45.52.52.82; E-mail: muguet@ensta.fr; Webpage: http://www.ensta.fr/ muguet

2 Molecules Editorial Office, Ocean University of Qingdao, Qingdao 266003, Shandong Province, China. Tel. \& Fax: (+86) 532203 1522; Tel. (+86) 5322031860 (office direct); E-mail: linsk@ouqd.edu.cn; Webpage: http://www.mdpi.org/lin

${ }^{3}$ Molecular Diversity Preservation International (MDPI), Matthaeusstrasse 11, CH-4057 Basel, Switzerland. Tel. (+41) 79322 3379; Fax (+41) 61302 8918; E-mail: lin@mdpi.org

${ }^{4}$ Brantford Chemicals Inc., 34 Spalding Dr., Brantford, ON, N3T 5W5, Canada. Tel: (+1) $519756-$ 8942, xt. 4992; Fax: (+1) 519 753-3051; E-mail: mcphee@mdpi.org

At a time when we are witnessing an explosion in the creation and distribution of electronic media, many librarians and readers still wish to have a journal they can store, feel and touch.... While it might be argued that this feeling may be a legacy of the past, it is nevertheless a factor that must be taken into account when competing with commercial journals. In order to increase the presence of MDPI journals in libraries, a joint MDPI/ENSTA printing project has been undertaken, whereby ENSTA is printing a limited edition of MDPI journals in its own high quality print shop. These printed editions obviously bring an element of prestige both to the journals and to the institution that is graciously helping to carry out such a task.

Critics of the OpenAccess journal concept have been eager to point out that only commercial journals have the means to provide printed editions, and that this need to provide a hard copy is the reason that justifies costly subscription fees. This project demonstrates that both this criticism and this explanation are unfounded.

It is tempting, although not completely accurate, to compare OpenAccess journals with the development of OpenSource software such as $\underline{\text { GNU }}$ and Linux, which have been implemented and 
used by ENSTA in a pioneering way since the early 90s. We strongly believe that OpenAccess scientific information is going to follow the same line of exponential success as OpenSource.

We would like to express our deepest gratitude to the direction of ENSTA, an institution both proud of its history, dating back to 1740, as well as of its name "National Higher School for Advanced Technologies", a reflection of its commitment to the future. Special thanks are due to Ingénieur Général Hubert Pasteau, Director of ENSTA, and to Dr. Elisabeth Crépon, former Director for Education and Research (now Director for International Relations at Ecole Polytechnique ).

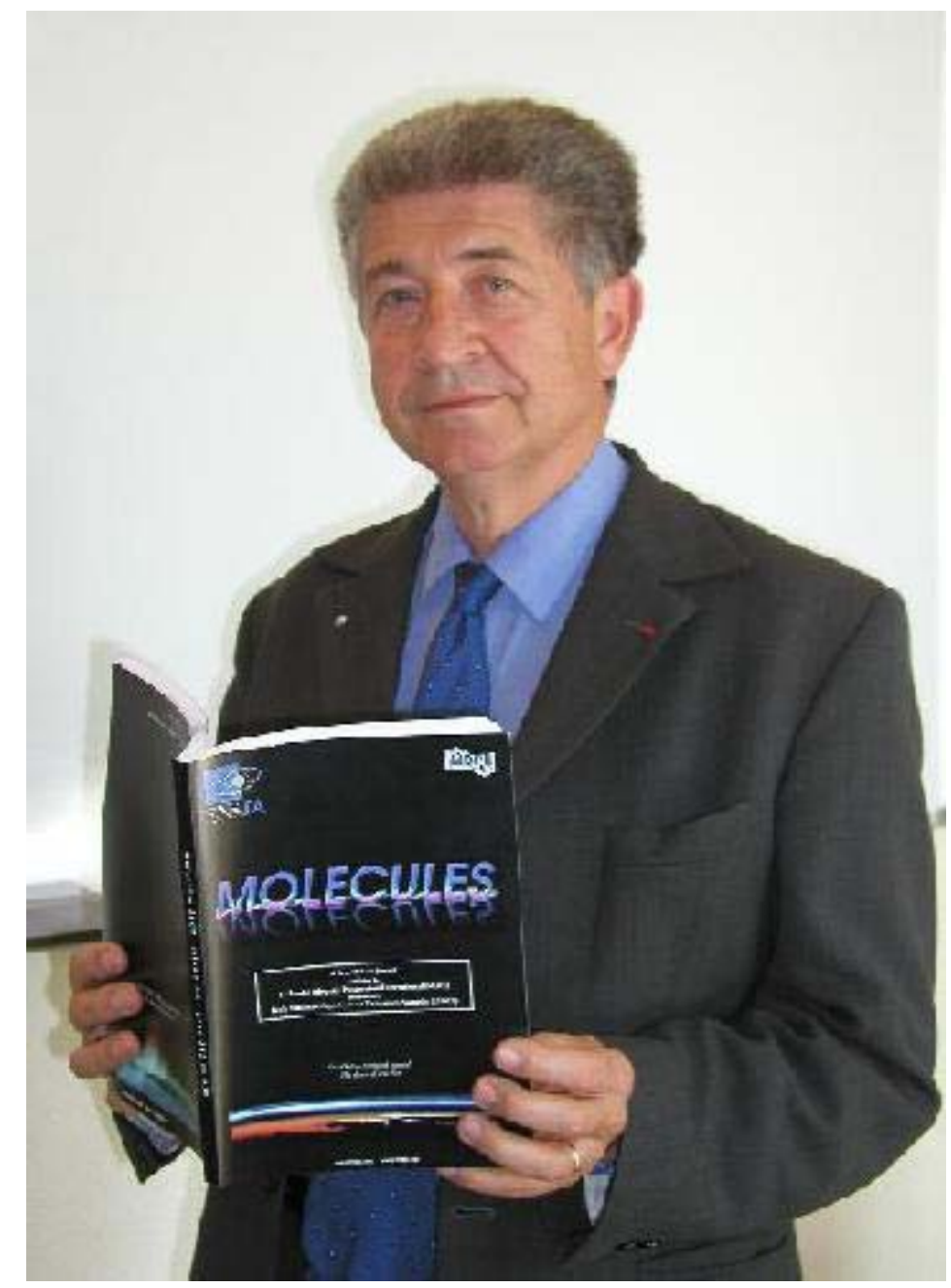

The director of ENSTA Ing. Gen. H. Pasteau with an issue of the MOLECULES journal

The cover design and general presentation have been conceived by Dr. Francis Muguet from the LMA/ENSTA laboratory. The page layout has been done by Md. Sylvie Di Stefano who is warmly thanked for her outstanding work. Management of the overall printing process has been done by $\mathrm{Mr}$. Richard Bouvignies whose remarkable dedication is gratefully acknowledged. 


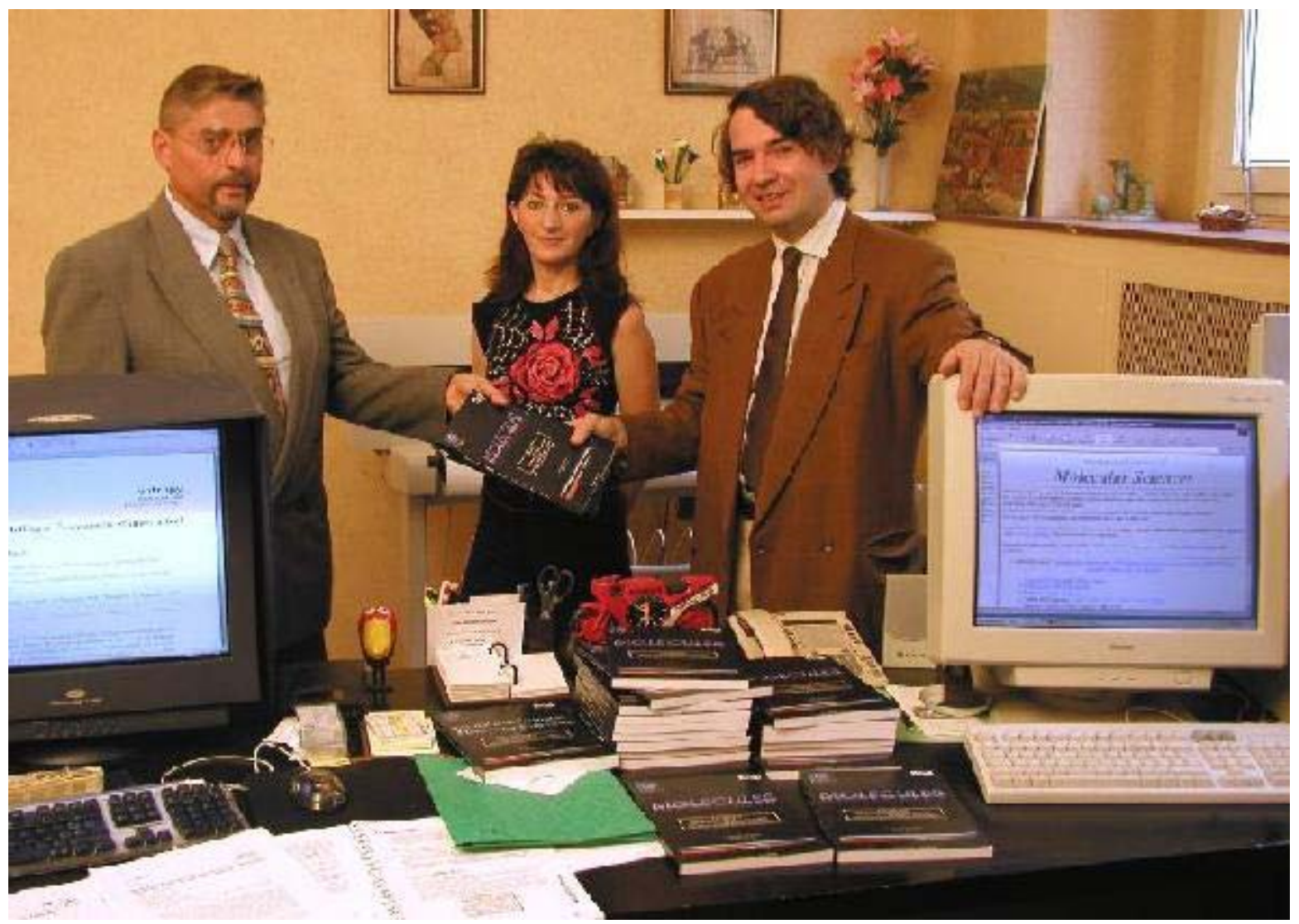

From left to right, at ENSTA's printing office:

Mr. Bouvignies, Md. Di Stefano and Dr. Muguet

We all believe that the availability of a printed edition will be most beneficial to all MDPI online journals. It should also be seen as encouraging news in support of new but growing international movements, like the Open Access Initiative or the "Gaining Independence" project, working together to help Open Access journals succeed.

(C) 2002 by MDPI (http://www.mdpi.org). Reproduction is permitted for noncommercial purposes. 